\title{
Pemodelan dan Verifikasi Formal Protokol EE-OLSR dengan UPPAAL CORA
}

\author{
Rachmat Wahid Saleh Insani*1, M. Reza M.I Pulungan ${ }^{2}$ \\ ${ }^{1}$ Prodi S2/S3 Ilmu Komputer, FMIPA UGM, Yogyakarta \\ ${ }^{3}$ Jurusan Ilmu Komputer dan Elektronika, FMIPA UGM, Yogyakarta \\ e-mail: *1 rachmat.wahid.s@gmail.com, pulungan@ugm.ac.id
}

\begin{abstract}
Abstrak
Sistem Information and Communication Technology (ICT) adalah suatu bagian hidup dari masyarakat yang sangat penting. Sistem ICT terus berkembang menjadi sistem yang kompleks dan besar. Protokol komunikasi adalah contoh sistem ICT yang digunakan oleh seluruh masyarakat pengguna Internet. Protokol OLSR adalah protokol komunikasi jaringan wireless yang bersifat proaktif, table-driven dan berbasis pada algoritma link-state. Protokol EE-OLSR adalah varian dari protokol OLSR yang dinyatakan mampu meningkatkan penggunaan energi tanpa adanya pengurangan pada performa.

Proses verifikasi protokol umumnya dilakukan dengan cara simulasi dan pengujian langsung. Namun proses tersebut tidak mampu memverifikasi bahwa tidak ada subtle error atau design flaw pada suatu protokol. Model checking merupakan metode algoritmik yang dijalankan secara fully-automatic untuk melakukan verifikasi pada sistem. UPPAAL adalah model checker tool untuk memodelkan, simulasi, dan verifikasi suatu sistem yang dimodelkan pada Timed Automata.

UPPAAL CORA adalah model checker tool untuk memverifikasi protokol yang telah dimodelkan ke bahasa pemodelan Linearly Priced Timed Automata, apakah protokol memenuhi properti energy efficient yang telah diformulasikan menggunakan bahasa spesifikasi formal dalam sintaks Weighted Computation Tree Logic. Teknik Model Checking terhadap protokol tersebut menghasilkan bukti bahwa protokol EE-OLSR memenuhi properti energy efficient hanya ketika lalu lintas pengiriman paket terjadi.
\end{abstract}

Kata kunci-pemodelan, verifikasi, EE-OLSR, UPPAAL CORA.

\section{Abstract}

Information and Communication Technology systems is a most important part of society. These systems are becoming more and more complex and are massively encroaching on daily life via the Internet and all kinds of embedded systems. Communication protocols are one of the ICT systems used by Internet users. OLSR protocol is a wireless network communication protocol with proactive, and based on link-state algorithm. EE-OLSR protocol is a variant of OLSR that is able to prolong the network lifetime without losses of performance.

Protocol verification process generally be done by simulation and testing. However, these processes unable to verify there are no subtle error or design flaw in protocol. Model Checking is an algorithmic method runs in fully automatic to verify a system. UPPAAL is a model checker tool to model, verify, and simulate a system in Timed Automata.

UPPAAL CORA is model checker tool to verify EE-OLSR protocol modelled in Linearly Priced Timed Automata, if the protocol satisfy the energy efficient property formulated by formal specification language in Weighted Computation Tree Logic syntax. Model Checking Technique to verify the protocols results in the protocol is satisfy the energy efficient property only when the packet transmission traffic happens.

Keywords- modeling, verification, EE-OLSR, UPPAAL CORA.

Received July 29 ${ }^{\text {th }}, 2015$; Revised January $1^{\text {st }}$, 2016; Accepted January 20 ${ }^{\text {th }}, 2016$ 


\section{PENDAHULUAN}

$\mathrm{M}_{\mathrm{s}=\mathrm{sin}}$ obile Ad Hoc Network (MANET) adalah jaringan komputer bersifat spontan, yang berkomunikasi melalui suatu media nirkabel. Setiap node dapat bergabung atau memisahkan diri kapan saja, serta bebas bergerak sesuai keinginan. MANET tidak memiliki infrastruktur terpusat, seluruh node yang berpartisipasi berfungsi sebagai node akhir dan router. Jaringan MANET memiliki sebuah topologi yang dinamis, dimana setiap node dapat bergerak secara acak, kondisi penyebaran radio berubah dengan cepat sepanjang waktu, serta bandwidth yang terbatas [1]. Sejak mobile host ditenagai oleh baterai, penggunaan energi baterai secara efisien sangatlah penting. Umur baterai dapat mempengaruhi performa komunikasi jaringan secara keseluruhan [2].

Optimized Link State Routing (OLSR) adalah protokol routing yang didasarkan pada link-state algorithm dan bersifat proaktif, protokol ini banyak digunakan dan dikembangkan sehingga berbagai macam studi terus dilakukan untuk memperbaiki serta meningkatkan kinerja protokol OLSR [3]. OLSR tradisional memberikan keunggulan dalam menemukan rute diantara dua node di dalam jaringan dalam waktu yang singkat dikarenakan polanya yang proaktif, namun OLSR dapat menghabiskan banyak sumber daya dalam proses pemilihan node MPR serta dalam pertukaran informasi Topology Control. Energy Efficient OLSR (EE-OLSR) adalah suatu protokol yang dinyatakan dapat meningkatkan tingkat efisiensi energi untuk memperpanjang umur jaringan tanpa adanya pengurangan pada performa [2].

Model Checking adalah suatu teknik verifikasi yang menyelidiki seluruh kemungkinan system state dengan cara brute force [4]. Model Checking juga merupakan sebuah metode algoritmik yang dijalankan secara fully-automatic untuk melakukan verifikasi pada sebuah sistem [5]. UPPAAL adalah suatu model checker tool yang digunakan untuk memodelkan, simulasi, dan melakukan verifikasi terhadap suatu sistem yang dimodelkan pada Timed Automata [6]. UPPAAL CORA adalah suatu varian dari UPPAAL untuk menganalisa Cost Optimal Reachability. UPPAAL CORA dikembangkan oleh tim yang telah mengembangkan UPPAAL sebelumnya. UPPAAL CORA menggunakan Linearly Priced Timed Automata (LPTA) sebagai bahasa pemodelannya. Penelitian ini dilakukan dengan memodelkan dan memverifikasi protokol EE-OLSR tersebut menggunakan tool model checker UPPAAL CORA.

\section{METODE PENELITIAN}

\subsection{Priced Timed Automata}

Priced Timed Automata (PTA), memiliki suatu definisi formal yaitu dimana X adalah kompulan clock, dan Priced Timed Automata pada X adalah sebuah annotated directed graph dengan vertex yang dapat dibedakan satu sama lain, yang disebut dengan initial location. Untuk membentuk suatu PTA, ditambahkan catatan pada edge dengan cost yang dibutuhkan untuk melakukan transisi, serta location dengan cost rate yang menunjukkan berapa cost yang dihabiskan ketika protokol berada di location tersebut.

Definisi 1. Secara formal, suatu PTA $A=(L, E, \mathcal{J}, \mathcal{L}, \mathcal{C})$

Dimana $L$ adalah himpunan location, $E$ adalah sekumpulan edge, $\mathcal{J}$ menetapkan invariant pada location, $\mathcal{L}$ merupakan labelling function, dan $\mathcal{C}$ adalah cost pada location dan edge.

Suatu contoh model Priced Timed Automata pada pemrosesan pesan HELLO ditunjukkan oleh Gambar 1.

IJCCS Vol. 10, No. 1, January 2016 : 93 - 102 


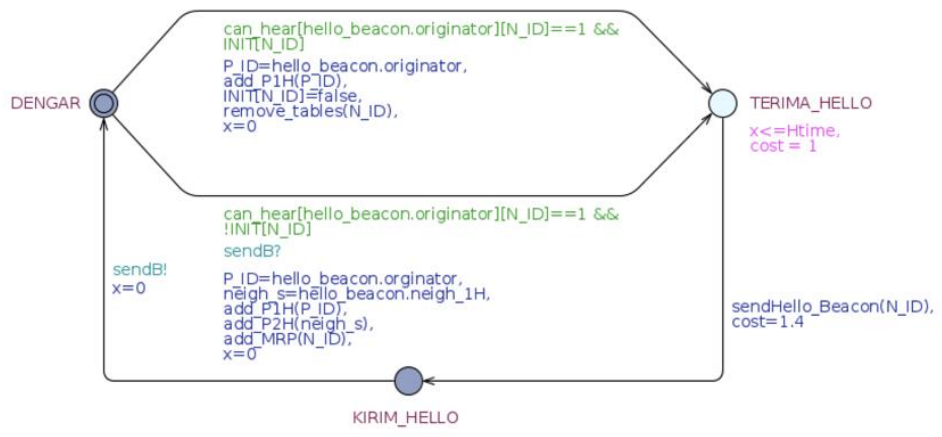

Gambar 1 Contoh Priced Timed Automata

\subsection{Weighted Computation Tree Logic}

Properti dari Priced Timed Automata diformalisasikan oleh rumus Weighted Computation Tree Logic (WCTL) [7].

Definisi 2. Jika diberikan AP sebagai himpunan atomic proposition, sintaks logic discrete WCTL adalah suatu grammar, yakni

$$
\varphi::=\sigma|\pi| \neg \varphi|\varphi \vee \varphi| \exists \mathrm{O} \varphi|\varphi \exists \bigcup \varphi| \varphi \forall \bigcup \varphi \mid z_{i} \cdot \varphi
$$

\subsection{UPPAAL CORA}

UPPAAL CORA adalah sebuah cabang dari UPPAAL untuk menganalisis Cost Optimal Reachability. Jika diberikan suatu model PTA, UPPAAL CORA memberikan informasi optimal path menuju suatu state yang memenuhi beberapa kondisi tujuan. Disini makna optimal adalah path dengan akumulasi cost yang paling rendah.

Penggunaan tool model checker UPPAAL CORA adalah untuk memverifikasi protokol EE-OLSR yang telah dimodelkan ke dalam bahasa pemodelan PTA, apakah suatu protokol dapat memenuhi properti energy efficient yang telah diformulasikan menggunakan bahasa spesifikasi formal melalui sintaks Weighted Computation Tree Logic (WCTL). UPPAAL CORA dapat menemukan path yang memiliki cost (pemakaian energi) paling minimal pada setiap proses di protokol EE-OLSR yang dimodelkan ke dalam bahasa pemodelan PTA.

\subsection{Energy Efficient Optimized Link State Routing Protocol (EE-OLSR)}

Protokol EE-OLSR merupakan varian dari protokol OLSR. Optimized Link State Routing Protocol (OLSR) adalah protokol routing yang berbasis pada algoritma link-state dan bersifat proaktif. Protokol ini melakukan pertukaran pesan secara berkala untuk menjaga informasi topologi jaringan di setiap node. OLSR memadatkan ukuran informasi yang dikirimkan didalam pesan kemudian mengurangi jumlah transmisi ulang untuk menyebarkan pesan tersebut di dalam jaringan.

Protokol OLSR bekerja dengan mengirimkan pesan kontrol ke seluruh node didalam jaringan melalui sekumpulan node MPR. Node MPR adalah sekumpulan node tetangga yang berjarak 1 hop yang bertugas untuk melakukan forwarding pesan yang diterima dari node MPR Selector. Node MPR Selector adalah node yang memilih sekumpulan node tersebut sebagai MPR.

Energy Efficient-OLSR (EE-OLSR) adalah suatu modifikasi dari protokol routing OLSR yang ditujukan untuk memperpanjang umur node di dalam jaringan. Modifikasi tersebut berada pada mekanisme pemilihan MPR yang berdasarkan pada konsep Willingness, untuk memperpanjang umur hidup jaringan tanpa kehilangan performa dalam hal throughput, end-toend delay atau overhead, pengecualian pada pemakaian energi yang disebabkan oleh overhearing yang dapat memperpanjang umur node tanpa mengurangi fungsi OLSR, serta ditambahkan suatu energy-aware metric pada proses pemilihan MPR dan pemilihan rute antara 
sumber dengan tujuan, yakni Minimum Drain Rate (MDR). Pesan kontrol yang disebarkan ke seluruh jaringan di protokol OLSR ada dua tipe, yakni pesan HELLO dan pesan Topology Control.

Pesan HELLO adalah pesan yang ditujukan agar node dapat mengetahui informasi node tetangga yang berjarak 1 hop darinya. Setiap node didalam jaringan mengirimkan pesan HELLO setiap 2 detik. Pesan HELLO tidak boleh di-forward oleh node penerima. Pesan HELLO berisi informasi mengenai: Message Type, tipe pesan, Originator Address, alamat ip dari node yang membuat pesan, Message Valid Time, jangka waktu hingga pesan ini dinyatakan tidak valid. One-hop neighbors of the Originator, alamat IP node tetangga dari node pembuat pesan.

Pesan TC adalah pesan kontrol yang ditujukan untuk mengetahui informasi rute serta informasi topologi. Setiap node melakukan broadcast pesan TC setiap 5 detik. Pesan TC harus disebarkan ke seluruh node didalam jaringan. Setiap pesan TC berisikan informasi, yakni: Message Type, tipe pesan, Message Originator, alamat IP pembuat pesan, Message Sequence Number, angka integer yang menunjukkan apakah pesan yang diterima adalah yang terbaru atau tidak, Time to Live, jumlah node didalam jaringan yang belum menerima pesan, Hops, jumlah hop dari pembuat pesan ke node penerima pesan, Validity Time, jangka waktu hingga pesan ini dinyatakan tidak valid, dan Advertised Neighbors Main Address, alamat IP dari node-node tetangga 1 hop dari pembuat pesan.

Protokol EE-OLSR memiliki sejumlah modifikasi pada mekanismenya, yakni Energy Aware Packet Forwarding, Mekanisme Pengaturan EA-Willingness, dan Pengecualian Overhearing. Energy Aware Packet Forwarding merupakan mekanisme yang terjadi pada proses pemilihan next hop untuk penyampaian paket data, dimana dilakukan suatu energy-aware metric yang ditujukan untuk memisahkan proses pemilihan MPR dari mekanisme pemilihan rute. Energy-aware metric tersebut adalah Minimum Drain Rate (MDR). Pengaturan Energy Aware Willingness adalah suatu mekanisme yang melibatkan pertimbangan energi pada pemilihan MPR. Pada saat suatu node melakukan transmisi paket unicast ke node lain, transmisi tersebut akan di-overhear oleh seluruh node tetangga dari node pengirim. Sehingga, node-node tetangga tersebut menghabiskan sejumlah energi walaupun paket tersebut tidak ditujukan pada mereka. Pengecualian Overhearing adalah suatu mekanisme dimana node yang berada pada jaringan dengan protokol EE-OLSR akan mengubah statusnya menjadi non-aktif ketika terjadi transmisi paket unicast di lingkungan sekitar node tersebut, sehingga node sekitar dari pasangan node yang sedang dalam transmisi pengiriman paket tidak menghabiskan energi karena overhear paket tersebut.

\subsection{Asumsi Pemodelan}

Setiap model merupakan sebuah abstraksi dari real system. Oleh karena itu, model yang dibangun harus mampu dijadikan sebuah asumsi skenario yang baik. Penelitian yang melibatkan Model Checking untuk membuat suatu model protokol komunikasi harus menyertakan suatu asumsi yang kuat terhadap sistem yang dibangun. Abstraksi yang diambil juga harus menitikberatkan pada protokol itu sendiri.

Sejumlah batasan juga diberikan agar model yang dibangun dapat terhindar dari keterbatasan di bidang Model Checking, yakni state space explosion. Penelitian sebelumnya membuktikan bahwa Model Checking terhadap protokol yang berjalan di MANET memiliki keterbatasan, yakni jumlah node yang dimodelkan tidak lebih dari 10 node [8]. Asumsi lain yang diperlukan adalah link antar node bersifat bi-directional. Secara umum, komunitas MANET membuat asumsi tersebut dengan tujuan untuk menyederhanakan protokol komunikasi dengan tidak menyertakan link yang uni-directional [9]. Penelitian ini bertujuan untuk memverifikasi apakah protokol EE-OLSR mampu memiliki umur node yang lebih panjang dari protokol OLSR tradisional melalui teknik Model Checking. Oleh karena itu keseluruhan jaringan terdiri dari sekumpulan node yang statis, dimana link failure tidak muncul. Kekurangan

IJCCS Vol. 10, No. 1, January 2016: $93-102$ 
yang sangat penting di sistem MANET bahkan dapat ditemukan pada skenario dengan jumlah node yang tidak banyak [10].

\subsection{Hubungan antar Model}

Pada penelitian ini, model yang dibuat terdiri dari 5 model, yakni model Waktu, OLSR, OLSR Queue, EE-OLSR, dan EE-OLSR Queue. Hubungan antar model ditunjukkan oleh Gambar 2. Model Waktu merepresentasikan kapan waktu yang diperlukan untuk mulai melakukan pembuatan pesan dan paket. Model EE-OLSR merepresentasikan perilaku node yang menggunakan jaringan protokol EE-OLSR. Model EE-OLSR Queue berfungsi untuk menyimpan informasi pesan maupun paket yang diterima oleh node dengan jaringan protokol EE-OLSR. Model OLSR menunjukkan perilaku dari node yang berada pada jaringan protokol OLSR. Model OLSR Queue berfungsi untuk menyimpan informasi pesan dan paket yang diterima oleh node protokol OLSR, serta membuat paket.

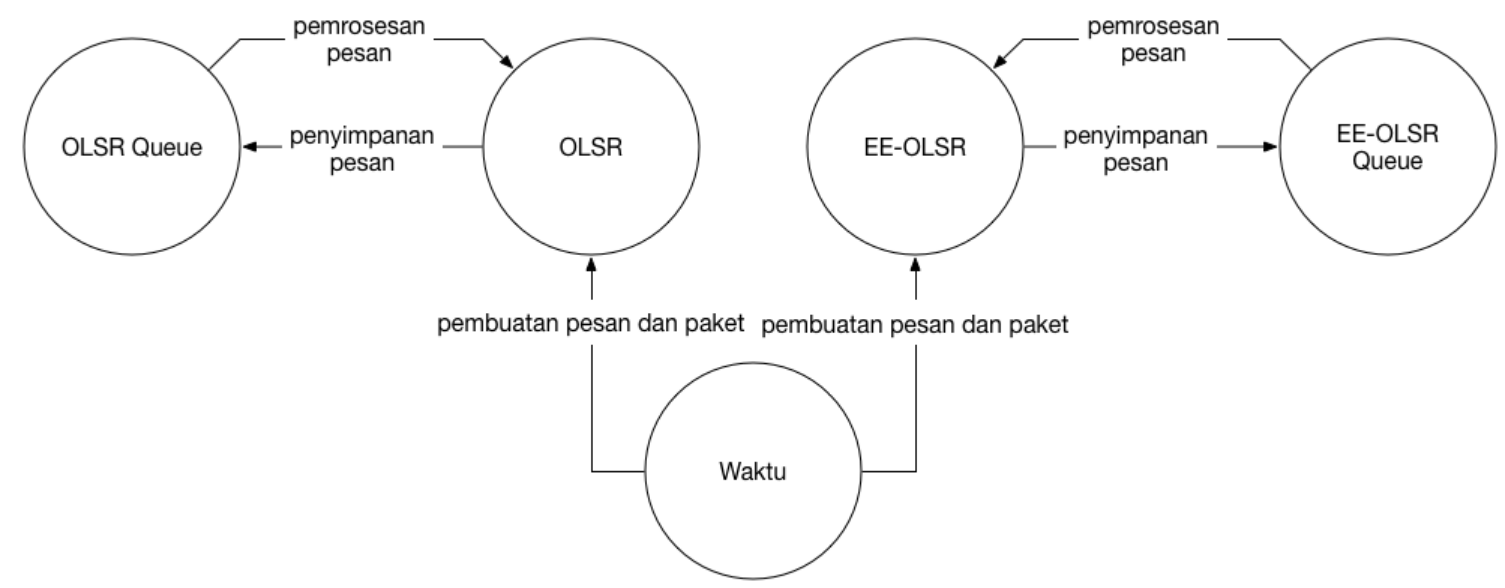

Gambar 2 Hubungan antar model

Model Waktu merepresentasikan suatu jadwal pengiriman pesan kontrol, yakni pesan HELLO dan pesan TC. Pengiriman tersebut dilakukan sesuai dengan interval masing-masing pesan. Model node EE-OLSR merepresentasikan perilaku utama dari node yang beroperasi di jaringan protokol EE-OLSR. Model EE-OLSR Queue bertugas untuk menyimpan pesan maupun paket yang diterima oleh node yang berjarak 1-hop dari pembuat pesan. Setiap pesan yang masuk akan disimpan di dalam suatu antrian. Model node OLSR merepresentasikan perilaku utama dari node yang beroperasi di jaringan protokol OLSR. Model OLSR Queue bertugas untuk menyimpan pesan maupun paket yang diterima oleh node pada protokol OLSR yang berjarak 1-hop dari pembuat pesan.

Secara detail, proses ini dimulai dengan seluruh node melalui model EE-OLSR dan OLSR melakukan pembuatan pesan HELLO ketika clock di model Waktu mencapai 2 detik. Model Waktu ditunjukkan oleh Gambar 3, model EE-OLSR ditunjukkan oleh Gambar 4, sedangkan model EE-OLSR Queue ditunjukkan oleh Gambar 5. Kemudian, node melakukan broadcast pesan tersebut ke seluruh node tetangga yang berjarak 1 hop darinya, proses broadcast pesan ini menghabiskan sejumlah energi, yakni energi transmit. Pesan HELLO yang diterima oleh suatu node, akan disimpan di dalam Queue. Node menghabiskan sejumlah energi ketika menerima pesan, dan dinyatakan dengan energi receive. Apabila node tersebut sedang berada dalam keadaan idle, maka EE-OLSR Queue dan OLSR Queue akan mengirimkan pesan tersebut menuju model EE-OLSR dan OLSR untuk diproses. Node akan melakukan pemeriksaan terhadap tipe pesan. Apabila tipe pesan adalah pesan HELLO, node akan melakukan update terhadap routing table bahwa node pembuat pesan tersebut berjarak 1 hop darinya. Pesan HELLO hanya dapat diterima oleh node yang berjarak 1 hop dari node pembuat 
pesan. Setelah node melakukan update terhadap routing table, maka pesan tidak akan diforward dan kemudian pesan dihapus.

Ketika node dalam keadaan idle, node akan melakukan pengiriman pesan TC setiap 5 detik. Pesan TC dikirimkan ke node yang berjarak 1 hop dari node pembuat pesan. Kemudian pesan TC tersebut di-forward kembali oleh node penerima ke node tetangga 1 hop darinya. Pesan TC akan di-forward hingga pesan tersebut tersebar di seluruh node didalam jaringan. Pesan TC akan disimpan di dalam Queue dari node penerima pesan. Pesan TC diproses ketika node tersebut sedang berada dalam keadaan idle, kemudian node melakukan pemeriksaan terhadap tipe pesan, apabila tipe pesan adalah pesan TC, maka pesan mulai diproses sesuai dengan tipe pesan. Node akan menghapus pesan apabila IP node penerima sama dengan IP node pembuat pesan. Jika IP node tidak sama dengan IP node pembuat pesan, dan jika informasi hops didalam pesan lebih kecil dari entri hops di routing table, maka node melakukan update terhadap routing table. Jika pesan telah di-forward sebelumnya, yang ditunjukkan oleh informasi forwarded $=1$, dan entri hops didalam pesan lebih besar sama dengan jumlah seluruh node dikurangi 1, serta informasi Time to Live pesan kurang dari sama dengan 1 maka pesan TC tersebut akan di-forward menuju node tetangga yang berjarak 1 hop dari node tersebut. Pesan TC akan berhenti di-forward apabila pesan tersebut pernah di-forward oleh node tersebut, atau entri hops didalam pesan lebih besar dari jumlah node dijaringan selain node pengirim, artinya pesan TC telah mengunjungi seluruh node di jaringan. Pesan TC juga tidak diforward apabila Time to Live pada pesan kurang dari 1.

Suatu paket mulai dikirim ketika clock telah mencapai angka 7000 milidetik. Ketika clock telah mencapai angka tersebut, seluruh node di jaringan telah mengetahui topologi seluruh node lainnya. Paket akan dibuat oleh model EE-OLSR Queue dan OLSR Queue. Setiap model tersebut melakukan assign IP pengirim sebagai ipk dan IP penerima paket sebagai ipt, informasi tersebut disimpan di paket. Kemudian, EE-OLSR Queue dan OLSR Queue memasukkan paket ke dalam antrian pesan. Apabila node sedang berada dalam keadaan idle maka kedua model Queue akan mengirimkan paket menuju model EE-OLSR dan OLSR. Apabila node yang menerima paket memiliki IP yang tidak sama dengan ipt di informasi paket, maka node tersebut bukanlah node tujuan, artinya paket akan di-forward.

Model EE-OLSR akan mencari path yang memiliki node dengan drain rate terendah untuk dijadikan sebagai node berikutnya yang harus menerima forwarding paket, informasi node ini terdapat di routing table yang disebut sebagai nhopip. Mekanisme ini dilakukan oleh UPPAAL CORA, karena tool ini menentukan dan mengambil transisi dengan nilai cost terendah secara otomatis. Sedangkan model OLSR memperoleh informasi nexthopip melalui pembaharuan routing table pada saat pesan TC diterima.

Kemudian, model EE-OLSR dan OLSR bersinkronisasi dengan model Queue dari node tetangga yang berjarak 1 hop dari node penerima paket yang memiliki IP yang sama dengan entri nhopip di routing table node tersebut. Apabila IP node sama dengan dip di informasi paket, maka paket berhasil dikirim.

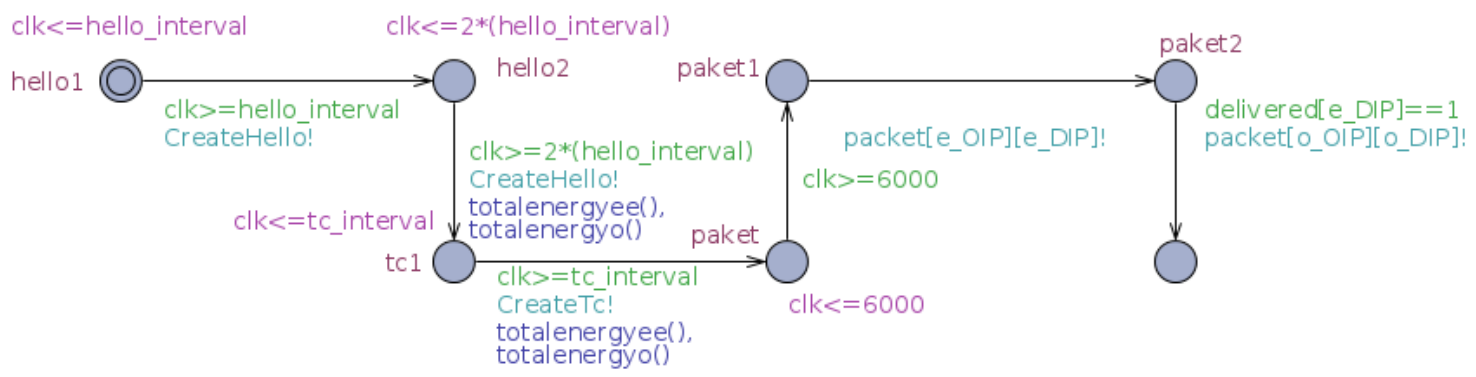

Gambar 3 Model Waktu

IJCCS Vol. 10, No. 1, January 2016: $93-102$ 


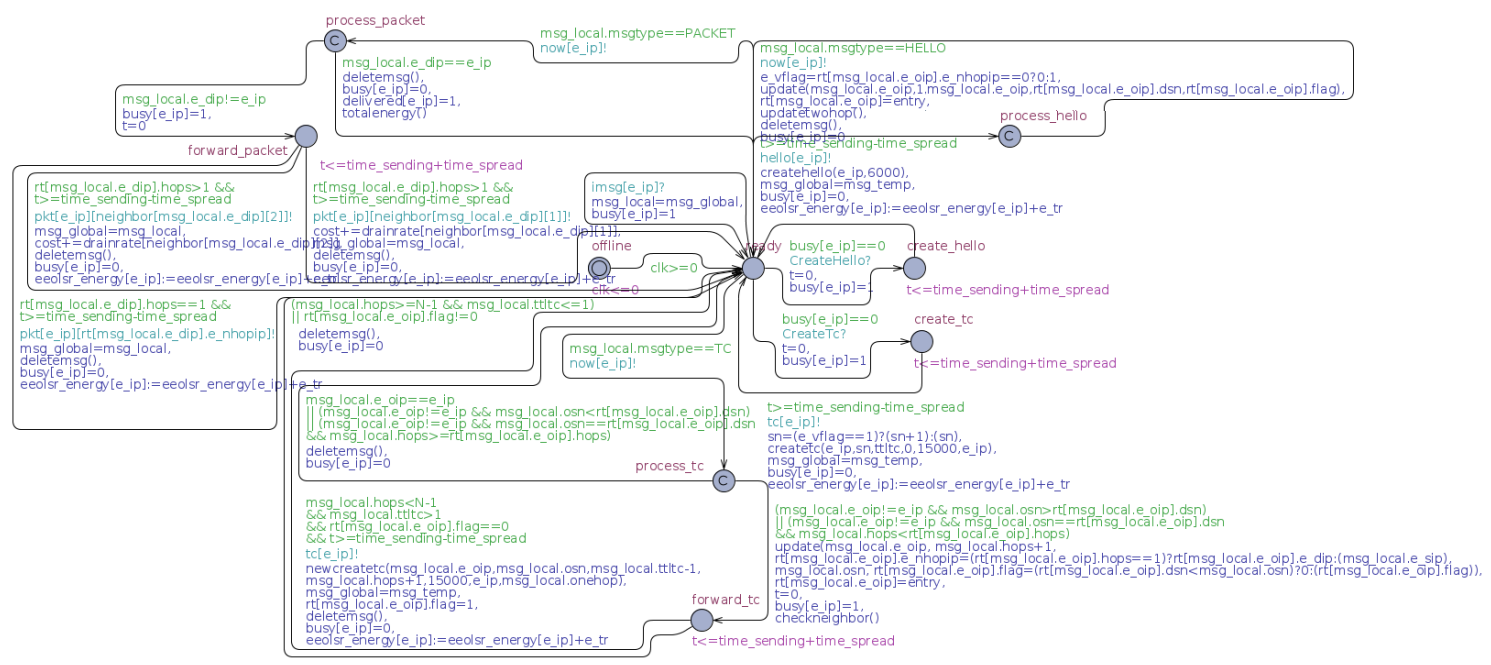

Gambar 4 Model EE-OLSR

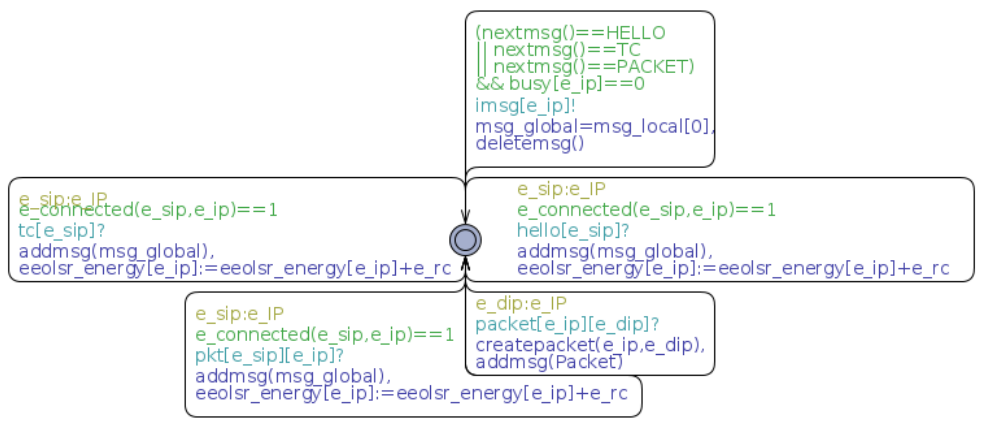

Gambar 5 Model EE-OLSR Queue

\section{HASIL DAN PEMBAHASAN}

Pada tahap ini dilakukan serangkaian percobaan untuk membuktikan bahwa model yang telah dibuat berhasil melakukan sejumlah urutan proses utama yang ada di protokol. Prosesproses tersebut antara lain seperti:

Neighbor Detection, pada proses ini, seluruh node mengetahui informasi $I P$ dari node tertangganya. Populating 2-hop Neighbor. Node mengetahui informasi IP dari node tetangga yang berjarak 2 hop darinya. Hasil verifikasi proses Neighbor Detection tersebut ditunjukkan oleh Gambar 6.

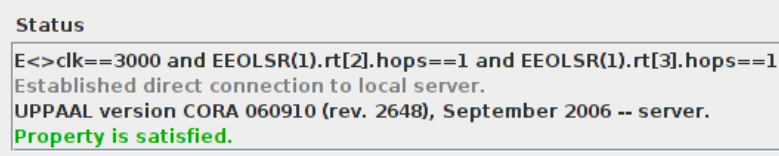

Gambar 6 Hasil verifikasi Neighbor Detection

Topology Discovery, node mengetahui informasi node tetangga dari seluruh node di jaringan. Hasil verifikasi proses Topology Discovery ditunjukkan oleh Gambar 7. 


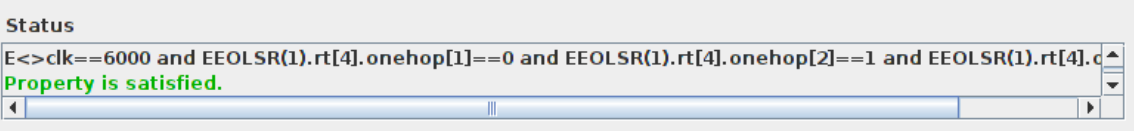

Gambar 7 Hasil verifikasi Topology Discovery

Optimal Route. Setiap node memperoleh informasi path terpendek antara node tersebut dengan node lain. Hasil verifikasi properti Optimal Route ditunjukkan oleh Gambar 8.

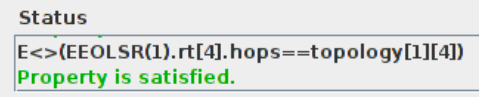

Gambar 8 Hasil verifikasi Optimal Route

Packet Delivery, suatu paket yang dikirim oleh suatu node dapat diterima di node yang ditujukan untuk paket tersebut. Hasil verifikasi properti Packet Delivery ditunjukkan oleh Gambar 9.

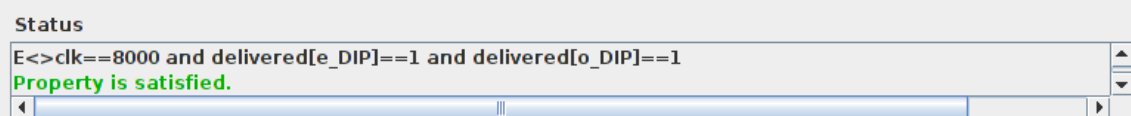

Gambar 9 Hasil verifikasi Packet Delivery

Energy Efficient. Energi yang dihabiskan oleh seluruh node di protokol EE-OLSR lebih kecil daripada energi yang dihabiskan oleh seluruh node di protokol OLSR. Hasil verifikasi properti energy efficient tersebut ditunjukkan oleh Gambar 10.

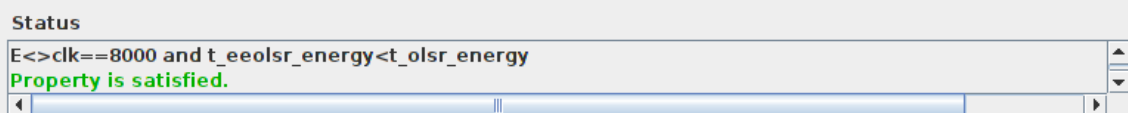

Gambar 10 Hasil verifikasi Energy Efficient

Penelitian ini juga melakukan percobaan perhitungan energi ketika node hanya melakukan pertukaran pesan kontrol, yakni pesan HELLO dan TC. Hasil verifikasi energi pada saat itu, kedua protokol menghabiskan energi dengan nilai yang sama. Hasil verifikasi proses energy efficient pada pemrosesan pesan kontrol tersebut ditunjukkan oleh Gambar 11 dan 12.

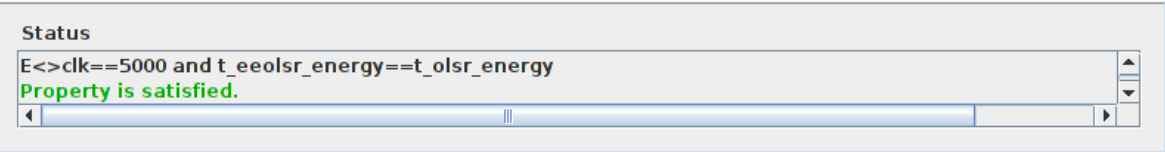

Gambar 11 Hasil verifikasi energi ketika pertukaran pesan HELLO

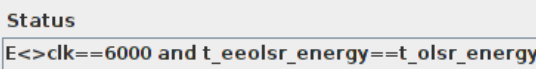

Gambar 12 Hasil verifikasi energi ketika pertukaran pesan TC 
Tabel 1 menunjukkan hasil dari verifikasi-verifikasi yang telah dilakukan pada penelitian ini.

Tabel 1 Daftar hasil verifikasi protokol

\begin{tabular}{|c|c|c|}
\hline Waktu (milidetik) & Proses pada protokol & Hasil verifikasi \\
\hline 2000 & Neighbor Detection & Satisfy \\
\hline 4000 & Populating 2 Hop Neighbor & Satisfy \\
\hline 5000 & Topology Discovery & Satisfy \\
\hline 7000 & Optimal Route & Satisfy \\
\hline 7000 & Packet Delivery & Satisfy \\
\hline 7000 & Energy Efficient & Satisfy \\
\hline
\end{tabular}

\section{KESIMPULAN}

Verifikasi protokol EE-OLSR yang dilakukan dengan memodelkan protokol menjadi tiga Priced Timed Automata dan diverifikasi secara otomatis menggunakan tool model checker UPPAAL CORA. Berdasarkan hasil verifikasi, protokol EE-OLSR mampu memenuhi properti energy efficient ketika lalu lintas pengiriman paket dilakukan. Namun, properti tersebut tidak dipenuhi apabila node masih melakukan pemrosesan pesan. Energi yang dihabiskan oleh kedua protokol pada saat pemrosesan pesan kontrol bernilai sama.

\section{SARAN}

Pada penelitian yang selanjutnya diharapkan mampu melakukan verifikasi protokol lain dengan properti lainnya. Pembahasan terhadap penggunaan PTA untuk memodelkan dan memverifikasi suatu protokol diharapkan dapat digunakan untuk penelitian terhadap protokolprotokol lainnya, terutama protokol yang memiliki ketergantungan aspek waktu dan cost berdasarkan spesifikasinya.

\section{UCAPAN TERIMA KASIH}

Penulis mengucapkan terima kasih kepada Allah swt, kedua orang tua, keluarga, dan para sahabat yang telah memberi dukungan pada penulis terhadap penelitian ini.

\section{DAFTAR PUSTAKA}

[1] Wibling, O., Parrow, J. dan Pears, A., 2004. Automatized Verification of Ad Hoc Routing Protocols. Formal Techniques for Networked and Distributed Systems, 325, pp.343-358.

[2] Rango, F. De, Fotino, M. dan Marano, S., 2008. EE-OLSR: Energy Efficient OLSR routing protocol for Mobile ad-hoc Networks. MILCOM 2008 - 2008 IEEE Military Communications Conference, pp.1-7.

[3] Jacquet, P. dan Clausen, T., 2001. Optimized link state routing protocol for ad hoc networks. ... , 2001. Ieee Inmic ..., 2001, pp.62-68. Available at: http://ieeexplore.ieee.org/xpls/abs_all.jsp?arnumber=995315. 
[4] Baier, C. dan Katoen, J.-P., 2008. Principles Of Model Checking, The MIT Press. Available at: http://mitpress.mit.edu/books/principles-model-checking.

[5] Berard, B. et al., 2010. System and Software Verification: Model Checking Techniques and Tools, Springer Publishing Company.

[6] Larsen, K.G., Pettersson, P. \& Yi, W., 1997. Uppaal in a nutshell. International Journal on Software Tools for Technology Transfer, 1(1-2), pp.134-152.

[7] Brihaye, T., Bruyère, V. dan françois Raskin, J., 2004. Model-Checking for Wei- ghted Timed Automata, in In Proceeding of FORMATS-FTRTFT'04, Lect. Notes Comput. Sci. 3253 , 277-292, Springer, pp. 277-292.

[8] Höfner, P. dan Mciver, A., 2013. Statistical Model Checking of Wireless Mesh Routing Protocols. In NASA Formal Methods. pp. 322-336.

[9] Prakash, R., 2001. A routing algorithm for wireless ad hoc networks with unidirectional links. Wireless Networks, 7(6), pp.617-625.

[10] Fehnker, A., van Glabbeek, R., Hofner, P., McIver, A., Portmann, M., dan Tan, W. L., 2011. Modelling and Analysis of AODV in UPPAAL. In 1st International Workshop on Rigorous Protocol Engineering. 